Article

\title{
Application of the Combined ANN and GA for Multi-Response Optimization of Cutting Parameters for the Turning of Glass Fiber-Reinforced Polymer Composites
}

\author{
Azhar Equbal 1, Mohammad Shamim ${ }^{2}$, Irfan Anjum Badruddin 3,4,*(D, Md. Israr Equbal ${ }^{5}$, \\ Anoop Kumar Sood ${ }^{6}$ (D), Nik Nazri Nik Ghazali ${ }^{7, *(D)}$ and Zahid A. Khan ${ }^{1}$ \\ 1 Department of Mechanical Engineering, Faculty of Engineering and Technology, Jamia Millia Islamia, \\ New Delhi 110025, India; azhr_eqbl06@yahoo.co.in (A.E.); zakhanusm@yahoo.com (Z.A.K.) \\ 2 Steel Melting Shop, Electro Steels Limited, Bokaro, Ranchi, Jharkhand 828129, India; \\ shamim2181@gmail.com \\ 3 Research Center for Advanced Materials Science (RCAMS), King Khalid University, P.O. Box 9004, \\ Abha 61413, Asir, Saudi Arabia \\ 4 Mechanical Engineering Department, College of Engineering, King Khalid University, \\ Abha 61413, Asir, Saudi Arabia \\ 5 Department of Mechanical Engineering, RTC Institute of Technology, Ranchi, Jharkhand 835219, India; \\ israr_equbal@yahoo.co.in \\ 6 Department of Manufacturing Engineering, National Institute of Foundry and Forge Technology, Hatia, \\ Ranchi 834003, Jharkhand, India; anoopkumarsood@gmail.com \\ 7 Department of Mechanical Engineering, Faculty of Engineering, University of Malaya, \\ Kuala Lumpur 50603, Malaysia \\ * Correspondence: magami.irfan@gmail.com (I.A.B.); nik_nazri@um.edu.my (N.N.N.G.)
}

Received: 9 April 2020; Accepted: 4 June 2020; Published: 9 June 2020

\begin{abstract}
Glass fiber-reinforced polymer (GFRP) composites find wide applications in automobile, aerospace, aircraft and marine industries due to their attractive properties such as lightness of weight, high strength-to-weight ratio, high stiffness, good dimensional stability and corrosion resistance. Although these materials are required in a wide range of applications, their non-homogeneous and anisotropic properties make their machining troublesome and consequently restrict their use. It is thus important to study not only the machinability of these materials but also to determine optimum cutting parameters to achieve optimum machining performance. The present work focuses on turning of the GFRP composites with an aim to determine the optimal cutting parameters that yield the optimum output responses. The effect of three cutting parameters, i.e., spindle rotational speed $(N)$, feed rate $(f)$ and depth of cut $(d)$ in conjunction with their interactions on three output responses, viz., Material Removal Rate $(M R R)$, Tool Wear Rate $(T W R)$, and Surface roughness $\left(R_{a}\right)$, is studied using full factorial design of experiments (FFDE). The statistical significance of the cutting parameters and their interactions is determined using analysis of variance (ANOVA). To relate the output response and cutting parameters, empirical models are also developed. Artificial Neural Network (ANN) combined with Genetic Algorithm (GA) is employed for multi-response optimization to simultaneously optimize the $M R R, T W R$ and $R_{a}$.
\end{abstract}

Keywords: glass fiber-reinforced polymer composite; turning; full factorial design of experiments; artificial neural network; genetic algorithm; multi-response optimization 


\section{Introduction}

Composite materials are manufactured by combining two or more different materials having specific chemical and physical properties. The composite materials possess properties superior to the individual constituent materials [1]. In a composite material, the constituent which is present in larger proportion is termed as the matrix and the constituent which is added to enhance the properties of the material is called the reinforcement. The matrix provides shape to the composite and distributes stress to the reinforcement, whereas the reinforcement provides high mechanical properties and reinforces the matrix in the preferred direction [2]. In recent years, composite materials, plastics and ceramics are being extensively used in the manufacturing industries. Composite materials provide a lot of benefits and that is why they play key role in accelerating the market economy. Composites have entered into various end-use segments and efforts to develop new composites for novel applications are an area of top priority [3]. Composite materials are normally lighter than metals and their specific strength and hardness are also usually better than metals due to presence of strong fibers. They also possess better conductivity, excellent corrosion and fatigue resistance and good thermal and acoustic insulation than the metals. Due to these notable properties, they are taking over the market and being used in various engineering and non-engineering applications. Composites find wide applications in a large number of areas including aerospace, aircrafts, marine, and transportation, domestic, medical, etc. Recently the GFRP composites have generated a lot of interest among the research fraternity [4-6]. Glass possesses various attractive features like its relatively low cost, its corrosion resistance, and its efficient manufacturing prospective. Glass fibers are formed by mixing raw materials like silica or silica-based oxides, melting them into the furnace and extruding the molten glass through bushing made of platinum or rhodium alloy with very fine holes and drawing the emerging fibers to the desired size at a constant speed. Subsequently, they are cooled or quenched by either using air or water jet/spray. A protective chemical coating is applied to the fibers to enrich their bonding and protect their surfaces. For application of composites, the diameter of fiber varies from 4 to $34 \mu \mathrm{m}$. The drawn and sized fibers are collected together by wounding onto a drum into a forming package which are then dried in an oven and are either palletized or further processed into yarn, tow or roving. Glass fibers have lower stiffness, reasonable strength and weight, and higher elongation as compared to other fibers. They are widely used in manufacturing of varieties of products including consumer goods, corrosion resistant products, electrical rods, tubes, components for chemical industries and marine accessories.

Everstine and Rogers [7] reported the first theoretical study on composite machining in which they explained the complete deformation and stress field and also tried to estimate the amount of force required for machining. An et al. [8] concluded that lesser blade wear and the best cutting quality glass fiber can be attained by considering optimal cutting parameters. Reddy [9] analyzed the effect of the cutting speed $(v), f$ and $d$ on $R_{a}$ and delamination damage of the GFRP composites and also proposed optimal factor setting for minimizing the selected responses. Davim et al. [10] studied the influence of cutting parameters on delamination while machining GFRP with two different matrixes. The Taguchi method and fuzzy logic approach was used Palanikumar et al. [11] to study the multi-objective optimization for machining of GFRP composites. At the optimum setting of machining parameters, an improvement in the performance characteristic was revealed by their study. Roy and Basu [12] developed empirical relations between turning parameters and the studied responses for machining of thermoplastics. Santhanakrishanan et al. [13] examined the surface behavior during machining of GFRP composites and found that higher spindle speed results in the higher surface roughness. Palanikumar [14] investigated machining of GFRP plastics using polycrystalline diamond (PCD) tool and found that $R_{a}$ was significantly affected by feed and cutting speed. Gupta and Kumar [15] employed grey relational analysis for simultaneously optimizing the material removal rate and surface finish during turning of GFRP with poly-crystalline diamond cutting tool. Kumar et al. [16] employed GA for multiple performance optimizations for machining of UD-GFRP composites using a PCD tool. Hanafi et al. [17] developed an ANN-based model to establish relationships between the cutting conditions and the surface roughness parameters during machining of fiber reinforced polyether 
etherketone (PEEK) CF30 with TiN-coated tools. The effect of machining parameters on surface finish obtained during the machining of short fiber reinforced thermoplastic was studied by Eriksen [18]. An empirical model relating the effect of cutting parameters on $R_{a}$ and $M R R$ in finish turning of GFRP pipes was given by Kini et al. [19].

The critical analysis shows that there are different parameters which affect machining of turned parts as presented in a fish bone diagram shown in Figure 1. A detailed review of the past literature reveals that the important factors which significantly affect the machining performance are cutting parameters, cutting tool, cutting environment and workpiece parameters. Among these the paramount impact is from cutting parameters like $N, f$ and $d$. The vital performance measures are MRR, TWR and $R_{a}$. The proper selection of processing conditions can lead to a significant improvement in output responses without any additional expenses.

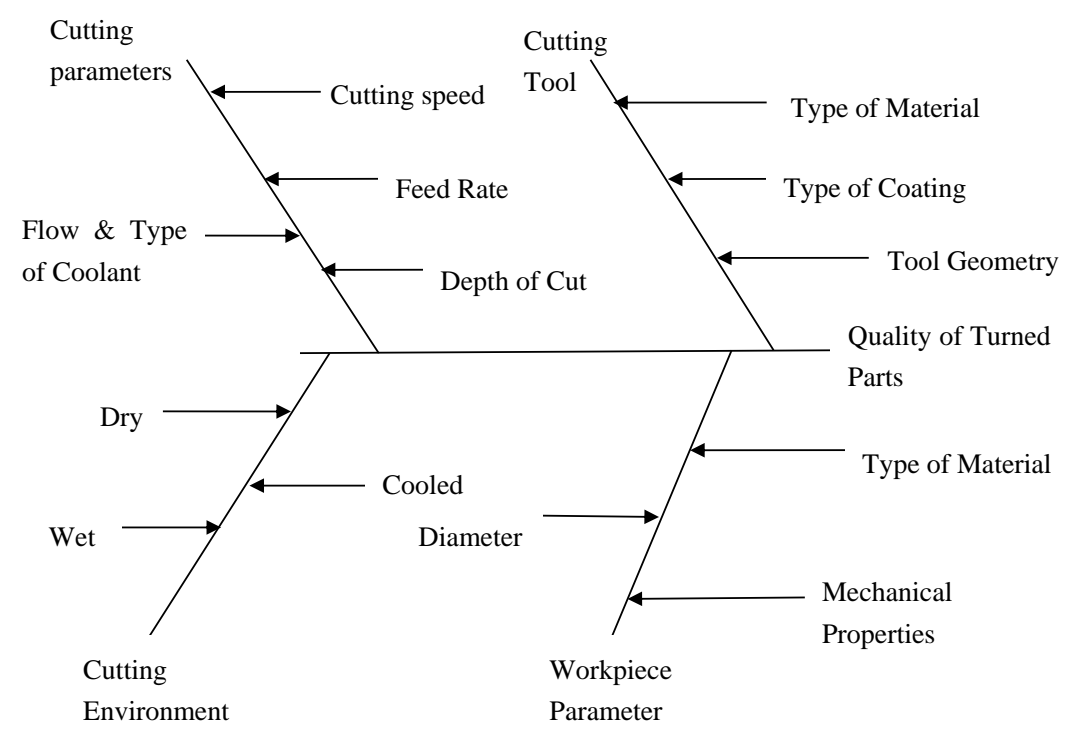

Figure 1. Fish bone diagram of parameters affecting quality of turned part [16].

High production rates, cost of production and a good surface finish are of prime importance in any machining process. This makes the problem multi-objective in nature as these requirements are contradictory in nature. To achieve this, the present study is focused on analyzing the effect of $N$, $f$ and $d$ on the MRR, TWR and $R_{a}$ simultaneously in the turning of the GFRP composite. A $3^{3}$ FFDE is used to design the combinations of cutting parameters to find the relative influence of each cutting parameter on the output responses considered in the present study. To determine the significance of the cutting parameters and their interactions on the output responses, ANOVA is used. Finally, to achieve the optimal setting of the cutting parameters for simultaneous optimization of $M R R, T W R$, and $R_{a}$, a combination of ANN and GA is used.

\section{Materials and Methodology}

\subsection{Workpiece Material and Cutting Tool}

The GFRP composite investigated in the present study consisted of 40\% epoxy (by volume) as matrix material and $60 \%$ of E-class (by volume) glass as reinforcement material. A specimen (Figure 2) of a 150-mm length and 50-mm diameter were used in the experimental investigation and they were procured from a composites manufacturing firm (Solar Chemicals and Engineers private limited, Kolkata, West Bengal, India). The specimen was manufactured by filament winding process. Filament winding is mainly used for manufacturing glass fiber pipes, cylinders, pressure vessels or tanks [20]. Mechanical properties of the epoxy and glass fiber as given by supplier are listed in Table 1. Machining studies were carried out by turning the GFRP composite material on a Qetcos-HMT Ltd. 20 center 
lathe-using Carbide K10 single point cutting tool (Figure 3). The composition and properties of the cutting tool are provided in Table 2.

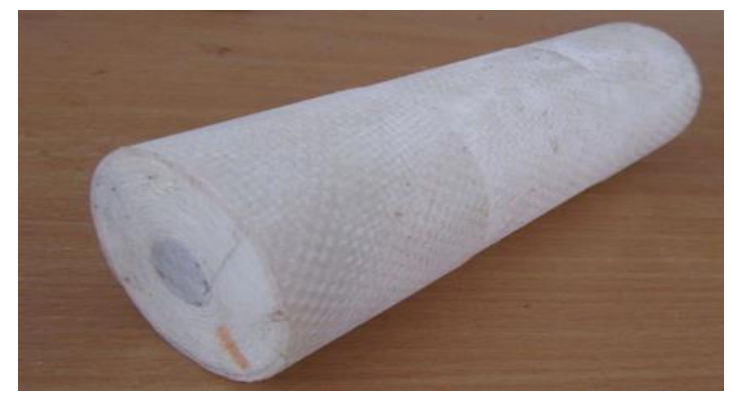

Figure 2. GFRP Specimen.

Table 1. Mechanical properties of Epoxy, Glass fiber and Composite material [21].

\begin{tabular}{cccccc}
\hline Material & $\begin{array}{c}\text { Tensile Strength } \\
(\mathbf{M P a})\end{array}$ & $\begin{array}{c}\text { Tensile Modulus } \\
\mathbf{( G P a )}\end{array}$ & $\begin{array}{c}\text { Shear Modulus } \\
\mathbf{( G P a )}\end{array}$ & $\begin{array}{c}\text { Poisson's } \\
\text { Ratio, } \boldsymbol{v}\end{array}$ & $\begin{array}{c}\text { Density } \\
\left(\mathbf{K g} / \mathbf{m}^{\mathbf{3}} \mathbf{)}\right.\end{array}$ \\
\hline Glass fiber & 1724 & 70 & 30 & 0.25 & 2500 \\
Epoxy & 83 & 6 & 2.3 & 0.35 & 1200 \\
Composite & 930 & 46 & 5 & 0.3 & 1876 \\
\hline
\end{tabular}

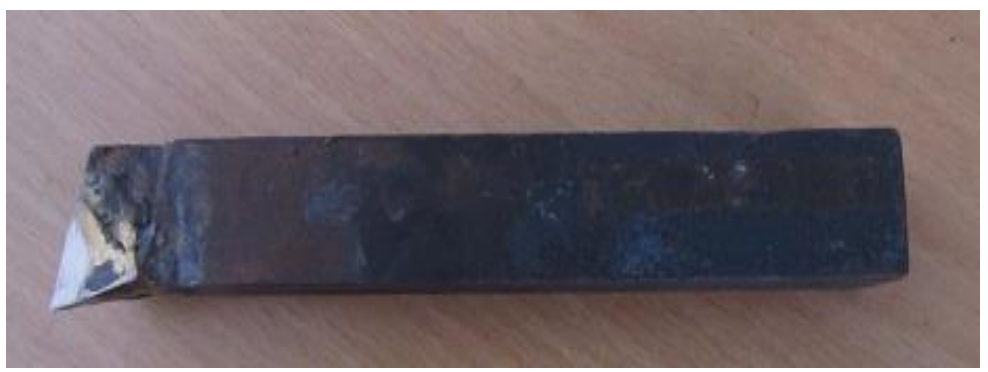

Figure 3. Carbide K10 single point cutting tool.

Table 2. Composition and properties of Carbide K10 tool [22].

\begin{tabular}{ccccccc}
\hline Grade & WC & Co & Density & Hardness Rockwell & T.S.R & Particle Size \\
\hline Unit & $\%$ & $\%$ & $\mathrm{~g} / \mathrm{cm}^{3}$ & HRA & $\mathrm{N} / \mathrm{mm}^{2}$ & $\mu \mathrm{m}$ \\
\hline K10 & 94 & 6.0 & 14.8 & 91.8 & 3000 & 1.0 \\
\hline
\end{tabular}

\subsection{Cuttingparameters}

The machining quality of turned parts is affected by various parameters like cutting parameter, cutting tool parameter, cutting environment and workpiece parameter. Among them, cutting parameters such as $N, f$, and $d$ are the most important $[8,9,23,24]$. Based on the previous research work and standard handbooks, three levels of these parameters were considered in the present study to develop the mathematical model to fix objective function for predicting three output responses, i.e., $M R R, T W R$ and $R_{a}$. The cutting parameters along with their levels are shown in Table 3. In the present work, for maximizing, larger-the-better (LTB) characteristic was chosen for MRR as the objective was to maximize it whereas, smaller-the-better (STB) characteristic was selected for both TWR and $R_{a}$ as their minimal values were desired. 
Table 3. Cutting parameters and their levels.

\begin{tabular}{cccccc}
\hline Cutting Parameter & Symbol & Unit & Level 1 & Level 2 & Level 3 \\
\hline Spindle rotational speed & $N$ & $\mathrm{Rpm}$ & 150 & 250 & 420 \\
Feed rate & $f$ & $\mathrm{~mm} / \mathrm{rev}$ & 0.10 & 0.20 & 0.30 \\
Depth of cut & $d$ & $\mathrm{~mm}$ & 2.00 & 3.00 & 4.00 \\
\hline
\end{tabular}

\subsection{Output Responses}

MRR: Higher material removal rate is desired in any turning operation. MRR is defined as the weight of material machined out in a unit time. In the present study $M R R$ (in $\mathrm{g} / \mathrm{s}$ ) was calculated from Equation (1).

$$
M R R=\frac{W_{i}-W_{f}}{t}
$$

where, $W_{i}$ and $W_{f}$ are the initial and final weights (in $g$ ) of the turned specimen, $t$ is the machining time in s.

For obtaining MRR, weight of the GFRP composite before and after machining was measured with the help of weighing machine (Mettler PM1200, Mettler, Esplanade, Kolkata, West Bengal, India). In each experiment, the GFRP specimen was turned up to a length of $50 \mathrm{~mm}$ on the lathe after setting the desired parameters, i.e., $f$ and $d$ on the machine. For each experiment, machining time was obtained using a stop watch.

TWR: During machining the rate at which the cutting edge of tool wears out defines the tool wear. In the present study, tool wear was taken as sum of both types of tool wear, i.e., flank wear and the crater wear.

Flank wear: It refers to the erosion of the portion of the tool which is in contact with the finished portion or workpiece.

Crater wear: It refers to the wear of the portion of tool which remains in contact with the chip during machining.

TWR was obtained from Equation (2).

$$
T W R=\frac{T_{i}-T_{f}}{t}
$$

where, $T_{i}$ and $T_{f}$ are the initial and final weights (in g) of the tool, and $t$ is the machining time in s.

Similar to $M R R$, for obtaining $T W R$, initial and final weights of the cutting tool were measured with the help of a weighing machine (Mettler PM1200) and machining time was recorded using a stop watch. Before measuring post operation weights, the machined specimen and the tool were properly cleaned to remove the chips that might have stuck to the specimen and the tool.

$R_{a}$ : Surface roughness at five different locations of the turned specimen was measured using Hommel Werke Turbo Wave V7.20 roughness tester and mean of these values was calculated and used as a representative value of the average surface roughness $\left(R_{a}\right)$.

\subsection{Design of Experiment}

For designing the experiment, a well-established technique of full factorial design is used. In a FFDE, all possible combinations of factor levels are used and corresponding output responses are measured [25]. Every single experimental setting is referred to as a run and the response measured is called an observation. The complete set of experiments or runs is termed as the design of experiments. The present work uses three cutting parameters/factors each at three different levels and, therefore, a $3^{3}$ full factorial design comprising of 27 experiments was employed as shown in Table 4 . In addition, the ANOVA was employed to ascertain significance of the cutting parameters and their interactions. 
Table $4.3^{3}$ full factorial design of experiments.

\begin{tabular}{cccc}
\hline Experiment No. & $\boldsymbol{N}$ (rpm) & $f(\mathbf{m m} / \mathbf{r e v})$ & $d(\mathbf{m m})$ \\
\hline 1 & 150 & 0.10 & 2.00 \\
2 & 150 & 0.10 & 3.00 \\
3 & 150 & 0.10 & 4.00 \\
4 & 150 & 0.20 & 2.00 \\
5 & 150 & 0.20 & 3.00 \\
6 & 150 & 0.20 & 4.00 \\
7 & 150 & 0.30 & 2.00 \\
8 & 150 & 0.30 & 3.00 \\
9 & 150 & 0.30 & 4.00 \\
10 & 250 & 0.10 & 2.00 \\
11 & 250 & 0.10 & 3.00 \\
12 & 250 & 0.10 & 4.00 \\
13 & 250 & 0.20 & 2.00 \\
14 & 250 & 0.20 & 3.00 \\
15 & 250 & 0.20 & 4.00 \\
16 & 250 & 0.30 & 2.00 \\
17 & 250 & 0.30 & 3.00 \\
18 & 250 & 0.30 & 4.00 \\
19 & 420 & 0.10 & 2.00 \\
20 & 420 & 0.10 & 3.00 \\
21 & 420 & 0.10 & 4.00 \\
22 & 420 & 0.20 & 2.00 \\
23 & 420 & 0.20 & 3.00 \\
24 & 420 & 0.20 & 4.00 \\
25 & 420 & 0.30 & 2.00 \\
26 & 420 & 0.30 & 3.00 \\
27 & 420 & 0.30 & 4.00 \\
\hline
\end{tabular}

\subsection{Problem Formulation with Hybrid ANN and GA Algorithm}

ANN is an interconnected group of nodes that is inspired by biological neural networks. The computations developed by ANNs are similar to the computing system performed by human or animal brains [26]. A simplified model in an ANN can transmit the signals between different nodes called artificial neurons. The connections in between the neurons are termed as edges. A neuron receives a signal in the form of a real number, processes it and computes the output using some non-linear function of sum of its inputs. Neurons and edges have weights that are adjusted as the learning proceeds and these weights can increase or decrease the strength of signal at a connection. The neurons are grouped into layers and different layers can perform different transformation on the input as received by them. The main goal of the ANN method is to solve the problem in a manner similar to that of human brain. However, ANN learns by examples and, therefore, it needs to be trained with a known example to acquire knowledge about it. After proper training, the network can be effectively used to solve the unknown problems [27]. In the present study, feed forward multi-layer network was used for programming the model. The input layer had three neurons; each corresponded to one cutting parameter, i.e., $N, f$ and $d$. The output layer consisted of three neurons one each for $M R R, T W R$ and $R_{a}$.

The GA is an unorthodox research algorithm which follows the concept of natural selection and genetics. Based on the objective function, GA executes random search on a population of potential solutions using the principle of survival of the fittest to generate better and better solutions to a problem [28]. The objective function is often termed as fitness function which is either to be maximized or minimized. For the optimization of a single objective problem, there is a single optimal solution, whereas in a multi-objective optimization problem, there are many sets of optimal solutions called non-dominating solutions. GA is a faster and more efficient method than the other traditional methods and can be used when the search space is very large and there are a large number of parameters 
involved. The research frame work using combined ANN and GA for multi-response optimization is shown in Figure 4. It is evident from Figure 4 that GA starts with initial population consisting of a group of chromosomes or solutions. Each chromosome in the population is real coded and contains the actual values of the cutting conditions fed by the ANN model to obtain the accurate fitness value. The fitness value of each solution is evaluated using fitness function. Based on the fitness value or survival of the fittest mechanism, solutions are selected by any selection processes like roulette wheel selection and tournament selection. Parents solutions are then recombined (crossover) to produce new offspring which are possibly the better solutions. Crossover can be accomplished by many ways like in the present work it has been obtained using two point crossover methods. All offspring is mutated with a certain probability and mutation gives small random changes to the individuals in the population which provide genetic diversity. The new offspring population, created by selection, crossover and mutation, is inserted into the population replacing the parents, producing a new generation. Many replacement techniques like elitist, generation-wise and steady-state replacement are used. If the optimization criteria are not met then creation of a new generation starts. Individuals are selected according to their fitness for the production of offspring. This cycle continues until the optimization criteria are reached. Once the stopping criterion is met then the non-dominated search stars to find the Pareto front based on the rank and crowding distance. Rank is given priority for shorting. When the situation comes where the fitness function has the same rank then crowding distance is applied for shorting. Where both rank and crowding distance are the same then randomly one of them is selected.

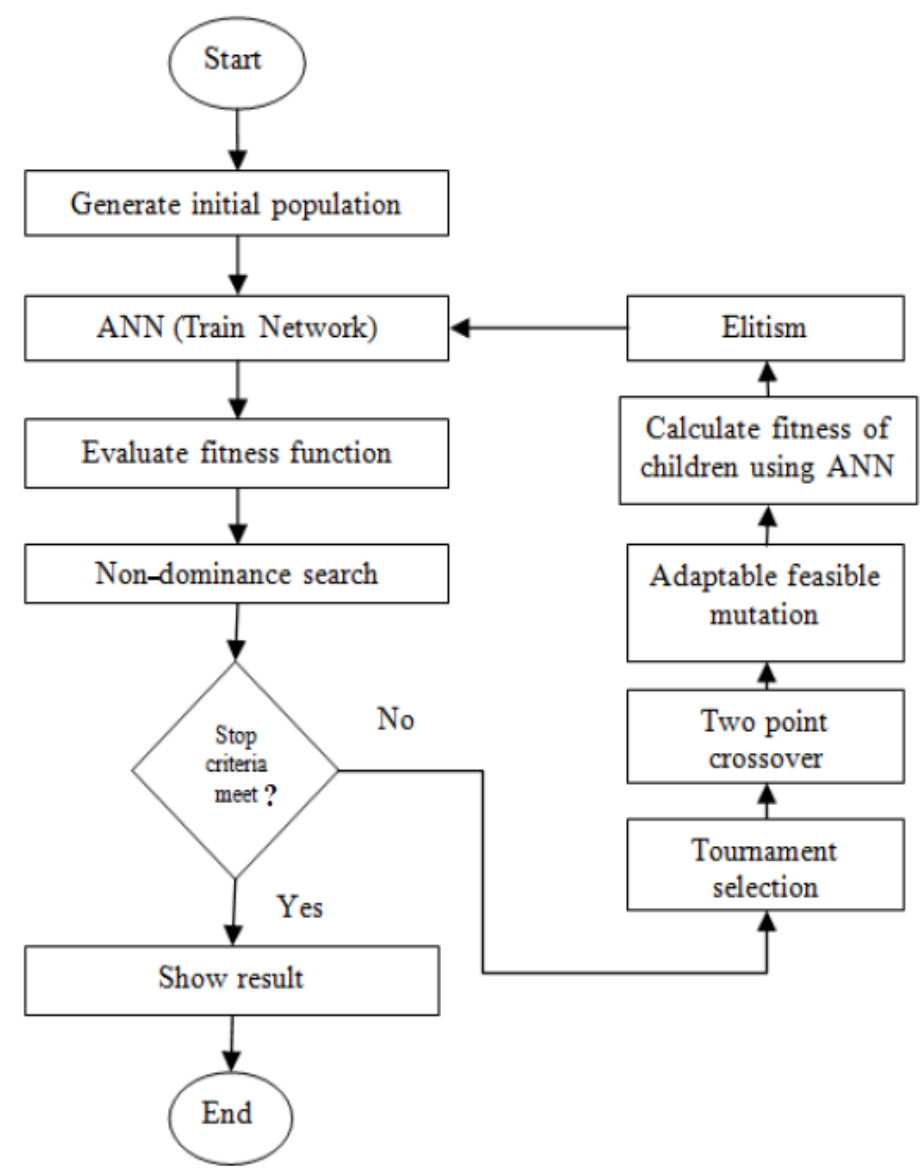

Figure 4. Research frame work using combined ANN and GA for multi-response optimization.

The proposed hybrid approach of ANN-based GA method combines the advantages of both the neural network and evolutionary computing method. For training the network, the input and output were first mapped into the range $[-1,1]$. To obtain the desired number of neurons in the hidden layer, 
various network configurations were tried by varying the number of neurons in the hidden layer from 3 to the number where the effective number of parameter and error became almost constant. Tansigmoid transfer function was used for determining the activation level of neuron except for output layer neurons for which a linear output transfer function was used so that output was not restricted to smaller values [29].

\section{Results and Discussion}

\subsection{Results}

To investigate the effect of cutting parameters, namely $N, f$ and $d$, on the output responses, i.e., $M R R, T W R$ and $R_{a}$ during turning of the GFRP composite, experiments were performed following the FFDE methodology. The output responses were measured as per the methodology explained in Section 2.3. Table 5 shows the experimental results during turning of the GFPR composite as per the selected FFDE. ANOVA at 95\% confidence level was used to study the relative influence of the cutting parameters and their interactions [30]. ANOVA for $M R R, T W R$ and $R_{a}$ are presented in Tables 6-8, respectively.

Table 5. Experimental results for turning of GFRP composite.

\begin{tabular}{ccccccc}
\hline Experiment No. & $\boldsymbol{N}(\mathbf{r p m})$ & $f(\mathbf{m m} / \mathbf{r e v})$ & $\boldsymbol{d}(\mathbf{m m})$ & $M R R(\mathrm{~g} / \mathbf{s})$ & $T W R(\mathbf{g} / \mathbf{s})$ & $\boldsymbol{R}_{\boldsymbol{a}}(\boldsymbol{\mu m})$ \\
\hline 1 & 150 & 0.10 & 2.00 & 3.823355 & 0.000658 & 5.6694 \\
2 & 150 & 0.10 & 3.00 & 7.061111 & 0.004575 & 3.8876 \\
3 & 150 & 0.10 & 4.00 & 8.749351 & 0.000325 & 4.3304 \\
4 & 150 & 0.20 & 2.00 & 10.1834 & 0.0028 & 5.6368 \\
5 & 150 & 0.20 & 3.00 & 13.2544 & 0.0052 & 3.8424 \\
6 & 150 & 0.20 & 4.00 & 14.462 & 0.002 & 4.5436 \\
7 & 150 & 0.30 & 2.00 & 16.04242 & 0.00303 & 9.73461 \\
8 & 150 & 0.30 & 3.00 & 17.9363 & 0.003704 & 8.1944 \\
9 & 150 & 0.30 & 4.00 & 21.85072 & 0.0034 & 8.7468 \\
10 & 250 & 0.10 & 2.00 & 8.6277 & 0.0011 & 5.0848 \\
11 & 250 & 0.10 & 3.00 & 13.73972 & 0.000709 & 5.512 \\
12 & 250 & 0.10 & 4.00 & 22.17847 & 0.003472 & 5.75 \\
13 & 250 & 0.20 & 2.00 & 14.33689 & 0.000971 & 5.6666 \\
14 & 250 & 0.20 & 3.00 & 20.81696 & 0.000893 & 5.9624 \\
15 & 250 & 0.20 & 4.00 & 29.701 & 0.004065 & 5.6568 \\
16 & 250 & 0.30 & 2.00 & 24.54103 & 0.005128 & 8.6888 \\
17 & 250 & 0.30 & 3.00 & 41.13 & 0.0025 & 8.1266 \\
18 & 250 & 0.30 & 4.00 & 60.602 & 0.009524 & 8.5208 \\
19 & 420 & 0.10 & 2.00 & 30.7997 & 0.0032 & 2.9757 \\
20 & 420 & 0.10 & 3.00 & 36.17119 & 0.005085 & 5.9754 \\
21 & 420 & 0.10 & 4.00 & 40.385 & 0.00283 & 5.1008 \\
22 & 420 & 0.20 & 2.00 & 40.541 & 0.005128 & 4.716 \\
23 & 420 & 0.20 & 3.00 & 58.52941 & 0.008248 & 7.9948 \\
24 & 420 & 0.20 & 4.00 & 73.145 & 0.006122 & 5.4842 \\
25 & 420 & 0.30 & 2.00 & 66.2284 & 0.008965 & 9.22 \\
26 & 420 & 0.30 & 3.00 & 88.1437 & 0.0112 & 10.1188 \\
27 & 420 & 0.30 & 4.00 & 101.6836 & 0.01165 & 9.536 \\
\hline
\end{tabular}

In Tables 6-8, DOF represents degrees of freedom, SS signifies sum of squares, and V refers to mean square. The significance of the factors and adequacy of regression was determined using $\mathrm{F}$ value. The possibility of $\mathrm{F}$ value being greater than the calculated $\mathrm{F}$ value due to noise was indicated by $p$-value. The terms having $p$-values less than 0.05 are significant. Based on the F value from the ANOVA tables, significant cutting parameters and their interaction for output responses were identified which are presented in Table 9. Polynomial regression analysis was used to determine the relations among cutting parameters and output responses and the degree of accuracy of the relations was ascertained 
by coefficient of determination $\left(R^{2}\right)$. The regression models obtained for $M R R, T W R$ and $R_{a}$ are given in Equations (3)-(5), respectively.

Table 6. ANOVA results for MRR.

\begin{tabular}{cccccc}
\hline Source of Variation & DOF & SS & V & F & $p$-Value \\
\hline$N$ & 2 & $10,490.32$ & 5245.16 & 259.70 & 0.000 \\
$f$ & 2 & 4015.43 & 2007.72 & 99.41 & 0.000 \\
$d$ & 2 & 1381.06 & 690.53 & 34.19 & 0.000 \\
$N f$ & 4 & 1115.32 & 278.83 & 13.81 & 0.001 \\
$N d$ & 4 & 378.41 & 94.60 & 4.68 & 0.030 \\
$F d$ & 4 & 202.79 & 50.70 & 2.51 & 0.125 \\
Error & 8 & 161.58 & 20.20 & & \\
Total & 26 & $17,744.92$ & \\
\hline \multicolumn{7}{c}{$=99.09 \%, R^{2}$ (adj.) $=97.04 \%$} \\
\hline
\end{tabular}

Table 7. ANOVA results for TWR.

\begin{tabular}{cccccc}
\hline Source of Variation & DOF & SS & V & F & $p$-Value \\
\hline$N$ & 2 & 0.000102 & $5.12 \times 10^{-5}$ & 83.37 & 0.000 \\
$f$ & 2 & $6.29 \times 10^{-5}$ & $3.15 \times 10^{-5}$ & 51.27 & 0.000 \\
$d$ & 2 & $7.7 \times 10^{-6}$ & $3.9 \times 10^{-6}$ & 6.28 & 0.023 \\
$N f$ & 4 & $2.77 \times 10^{-5}$ & $6.9 \times 10^{-6}$ & 11.29 & 0.002 \\
$N d$ & 4 & $2.81 \times 10^{-5}$ & 0.000007 & 11.47 & 0.002 \\
$F d$ & 4 & $5.4 \times 10^{-6}$ & $1.4 \times 10^{-6}$ & 2.21 & 0.158 \\
Error & 8 & $4.9 \times 10^{-6}$ & $6.0 \times 10^{-7}$ & 83.37 & \\
Total & 26 & 0.000239 & & \\
\hline \multicolumn{7}{c}{$R^{2}=97.95 \%, R^{2}$ (adj.) $=93.33 \%$} \\
\hline
\end{tabular}

Table 8. ANOVA results for $R_{a}$.

\begin{tabular}{cccccc}
\hline Source of Variation & DOF & SS & V & F & $p$-Value \\
\hline$N$ & 2 & 1.577 & 0.7885 & 17.7 & 0.001 \\
$f$ & 2 & 80.3289 & 40.1644 & 901.63 & 0.000 \\
$d$ & 2 & 0.2897 & 0.1449 & 3.25 & 0.093 \\
$N f$ & 4 & 2.0543 & 0.5136 & 11.53 & 0.002 \\
$N d$ & 4 & 4.6856 & 1.1714 & 26.3 & 0.000 \\
$F d$ & 4 & 0.5893 & 0.1473 & 3.31 & 0.070 \\
Error & 8 & 0.3564 & 0.0445 & 0.0445 & \\
Total & 26 & 89.8811 & & & \\
\hline \multicolumn{7}{c}{$R^{2}=99.60 \%, R^{2}$ (adj.) $=98.71 \%$} \\
\hline
\end{tabular}

Table 9. Significant cutting parameters and their interactions for $M R R, T W R$ and $R_{a}$.

\begin{tabular}{cccc}
\hline \multirow{2}{*}{ Parameter/Interactions } & \multicolumn{3}{c}{ Output Response } \\
\cline { 2 - 4 } & $\boldsymbol{M R R}$ & $\boldsymbol{T W R}$ & $\boldsymbol{R}_{\boldsymbol{a}}$ \\
\hline Significant Cutting Parameter & $N, f$, and $d$ & $N, f$, and $d$ & $N$ and $f$ \\
Significant Interactions & $N f$ and $N d$ & $N f$ and $N d$ & $N f$ and $N d$ \\
\hline
\end{tabular}

Figure 5a-c depict the normality plot for $M R R, T W R$ and $R_{a}$, respectively. It can be seen from these figures that $p$-value is greater than 0.05 for all the selected output responses which signifies that residual follows normal distribution and developed regression models, i.e., Equations (3)-(5) are 
suitable for predicting the values of the corresponding output response for given values of cutting parameters accurately.

$$
\begin{gathered}
\text { MRR }=-2.91383-5.73019 N-3.93833 f-1.6812 d+9.37535 N f+5.2193 \mathrm{Nd} \\
\text { TWR }=0.00214215-0.00133067 \mathrm{~N}-0.000846556 f-0.000167833 d+0.001352 \mathrm{Nf}+0.000331 \mathrm{Nd} \\
R_{a}=2.44255+0.143564 \mathrm{~N}+1.75849 f+0.0621325 \mathrm{~N} f+0.0140796 \mathrm{Nd}
\end{gathered}
$$

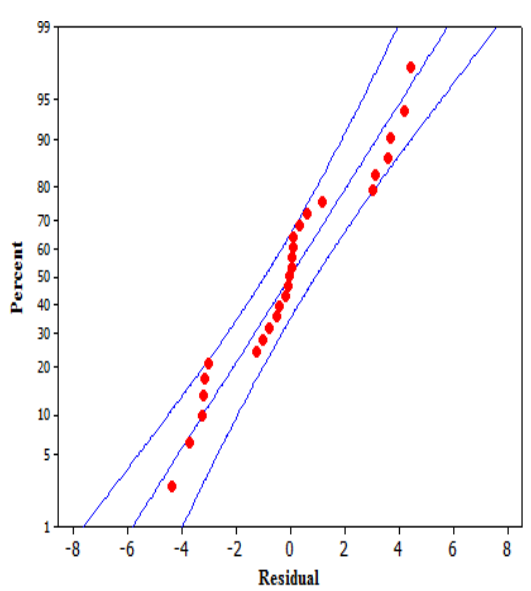

(a)
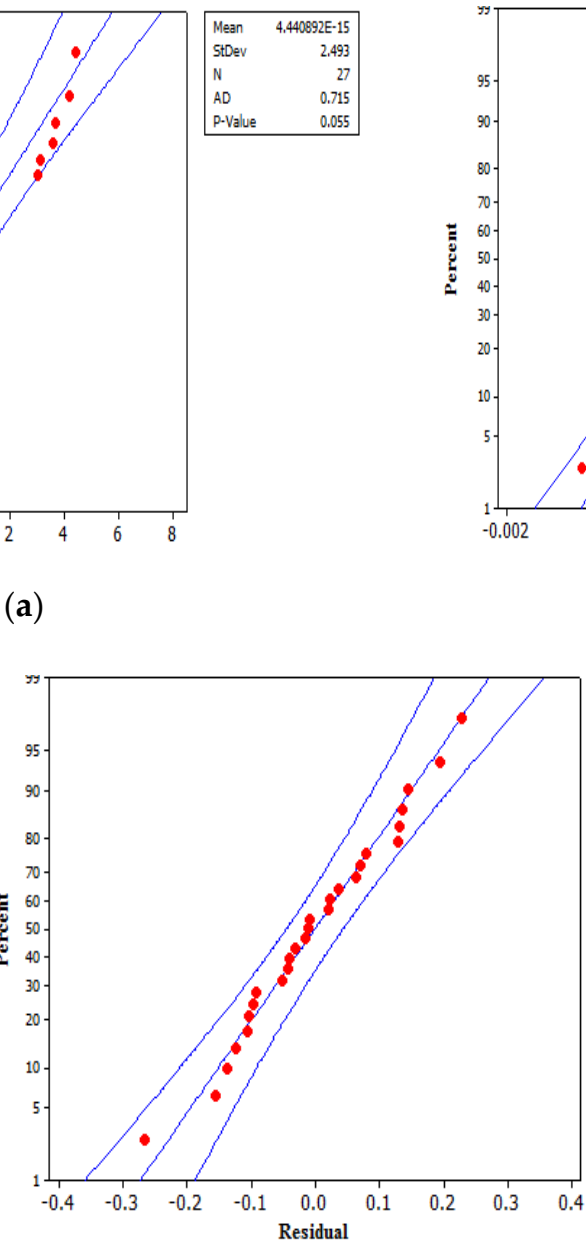

(c)

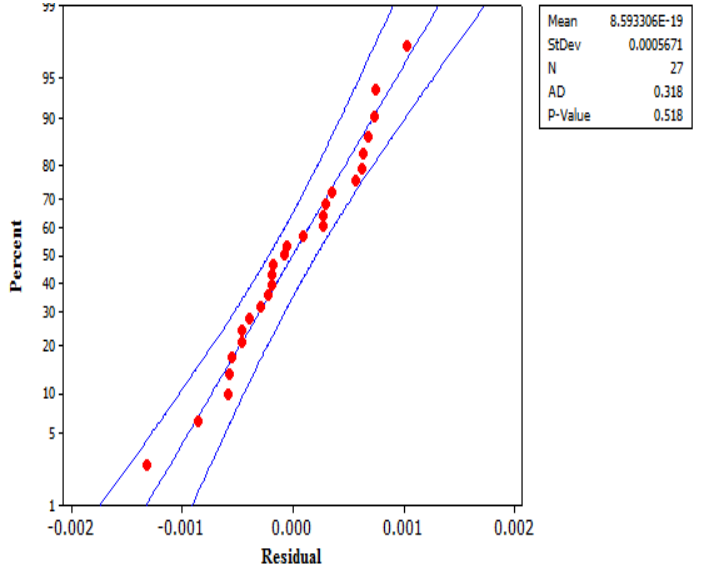

(b)

Figure 5. Normality plots for (a) $M R R$ (b) $T W R$ and (c) $R_{a}$.

The ANOVA results shown in Table 6 and surface plot depicted in Figure 6 reveal that $N, f, d$ and the interactions $N f$ and $N d$ have significant effect on MRR. Figure 6a shows that MRR increases with increase in $N$ and $f$. However, the effect of $N$ is more significant because as it increases the specimen takes less time to complete one revolution and simultaneous increase in the $f$ enables the tool to traverse faster which results in the fast removal of material in the same duration. Figure $6 \mathrm{~b}, \mathrm{c}$ also show that $M R R$ increases with increase in $N, f$ and $d$. An increase in $d$ also facilitates the maximum removal of materials. 

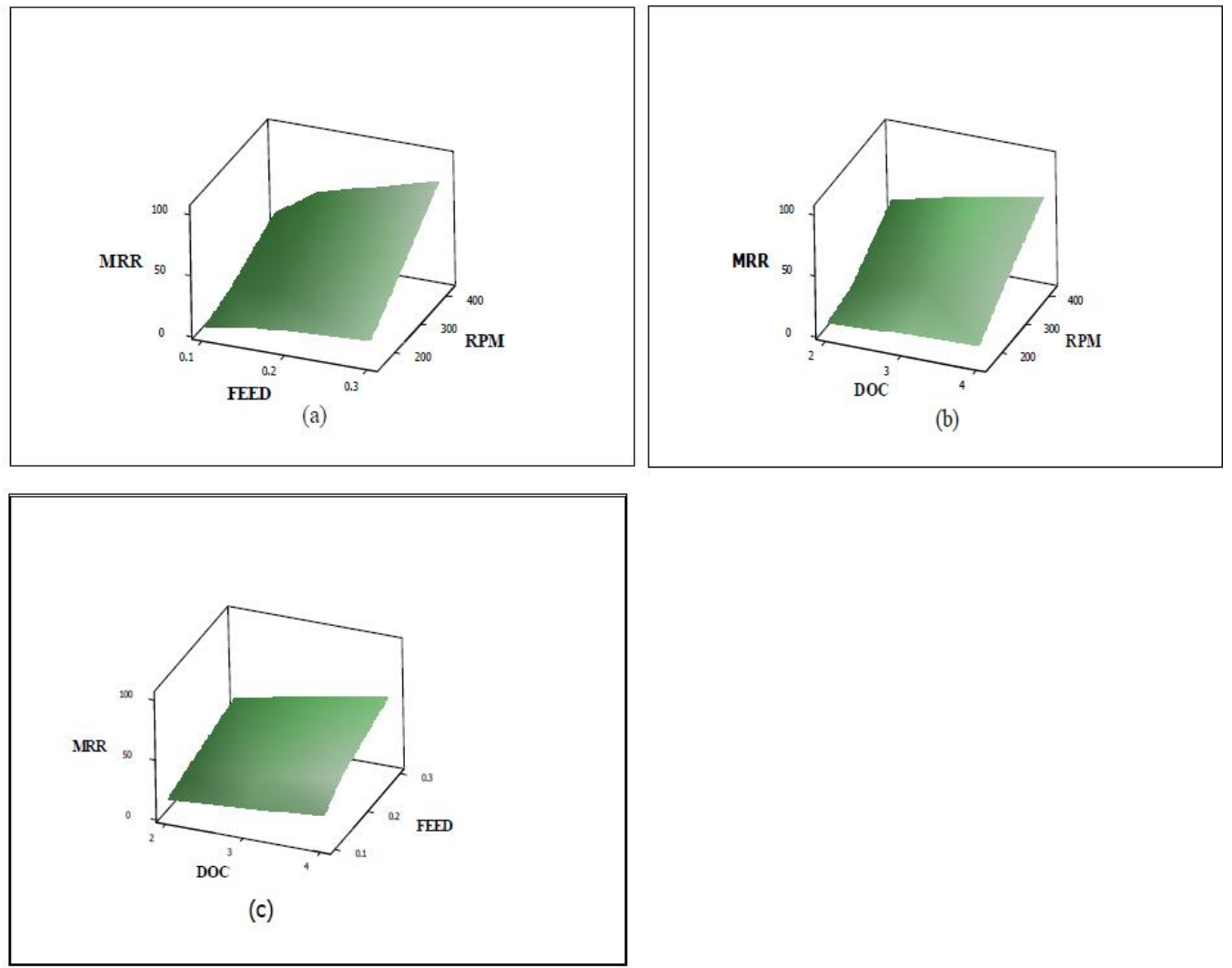

Figure 6. Surface plot of $M R R$ (a) $M R R$ Vs. $f, N(\mathbf{b}) M R R$ Vs. $d, N(\mathbf{c}) M R R$ Vs. $d, f$.

Table 7 presents the ANOVA results for TWR and the surface plot for the TWR is shown in Figure 7. It is evident from Table 7 and Figure 7 that $N, f$ and $d$ and the interactions $N f$ and $N d$ have a significant effect on TWR. Figure 7a clearly shows that with increase in $N$ and $f, T W R$ increases. An increase in $N$ generates more heat in the region between the tool and the workpiece which causes more tool wear. Increase in the $f$ leads to chatter and complete machining of the workpiece cannot be achieved at the faster tool traverse which is the reason for higher tool flank wear. Thus, $N$ are $f$ are the most influential factors for TWR. Figure 7b, c depict that among the three cutting parameters, the effect of $d$ is the least significant factor for TWR. If $N$ is kept constant then heat generation does not increase immensely even though $d$ is increased and therefore TWR does not get affected significantly by $d$.

The ANOVA results and surface plot displayed in Table 8 and Figure 8 , respectively, reveal that the $N, f$ and the interactions $N f$ and $N d$ have a significant effect on $R_{a} . R_{a}$ varies nonlinearly with increase in $N$ as revealed by Figure 8a. $R_{a}$ reduces with increase in $N$ up to a particular level. Further increase in $N$ increases $R_{a}$ and hence the spindle rotational speeds at which $R_{a}$ increases are regarded critical for machining GFRP composites. This happens because, as $N$ increases, the time available to cut the composite is less and with $f$ kept at constant value the tool may not be able to cut the composite at higher speed which may cause some un-machined composite to remain on the surface leading to higher $R_{a}$. Normally, the effect of the $d$ is less severe in composite machining. Figure $8 \mathrm{~b}$ emphasizes that, for a better surface finish, a higher value of $d$ should be used. A lower value of $d$ may lead to partial removal of fibers from the composite matrix which in turn could be the reason for poor surface finish or higher $R_{a}$. At higher $d$, fiber removal can be done completely and $R_{a}$ can be minimized. Figure $8 \mathrm{c}$ indicates that $R_{a}$ is lower at minimum $f$ as the machining is properly controlled and it can also be asserted that at a lower $f$ the strain rate will also be lower. Figure $8 \mathrm{~b}$ also reveals that $d$ has the minimal effect on $R_{a}$. Hence, it can be said that the interaction between $f$ and $d$, i.e., $f d$ is not significant for $R_{a}$ and it can also be verified from the ANOVA results given in Table 8. 

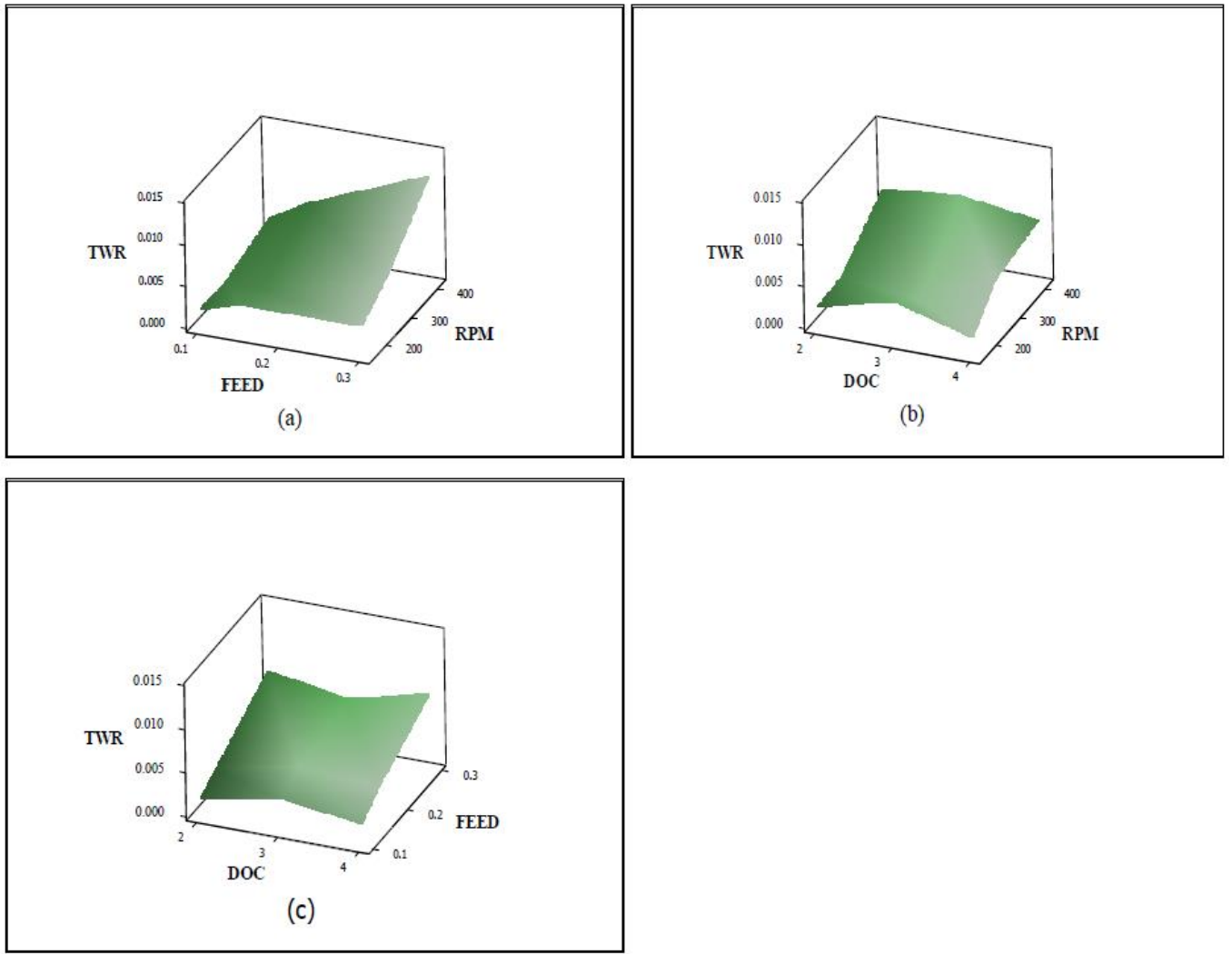

Figure 7. Surface plot of TWR (a) TWR Vs. $f, N$ (b) TWR Vs. $d, N$ (c) TWR Vs. $d, f$.
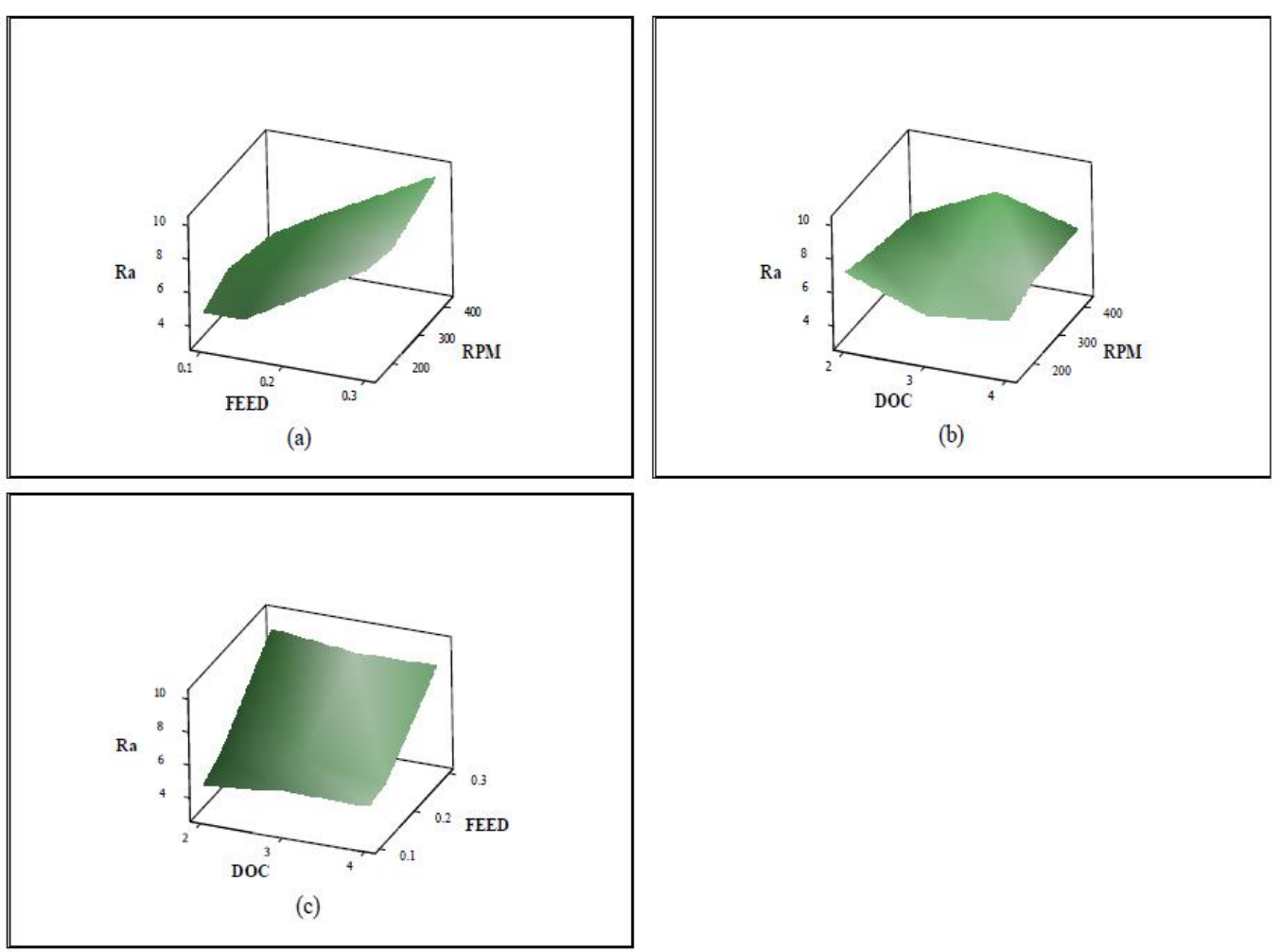

Figure 8. Surface plot of $R_{a}(\mathbf{a}) R_{a}$ Vs. $f, N(\mathbf{b}) R_{a}$ Vs. $d, N$ (c) $R_{a}$ Vs. $d, f$. 


\subsection{Multi-Response Optimization Using ANN and GA}

The results of network training by taking various numbers of neurons in hidden layer 1 are given in Table 10.

Table 10. Training result for hidden layer 1.

\begin{tabular}{cccccc}
\hline Neurons & Epochs & $\begin{array}{c}\text { Sum of } \\
\text { Square Error }\end{array}$ & $\begin{array}{c}\text { Effective } \\
\text { Parameters }\end{array}$ & $\begin{array}{c}\text { Total Number } \\
\text { of Parameter }\end{array}$ & $\begin{array}{c}\text { Sum Square } \\
\text { Parameter }\end{array}$ \\
\hline 3 & 252 & 5.06 & 24 & 13.3991 & 4.1186 \\
4 & 212 & 5.07 & 31 & 13.4922 & 4.0818 \\
5 & 345 & 5.07 & 38 & 13.5069 & 4.0609 \\
6 & 432 & 5.08 & 45 & 13.509 & 4.0503 \\
7 & 506 & 5.16 & 52 & 13.0428 & 3.8384 \\
8 & 539 & 5.16 & 59 & 13.0309 & 3.8334 \\
9 & 610 & 5.16 & 66 & 13.0223 & 3.8295 \\
10 & 809 & 5.16 & 73 & 13.0157 & 3.8265 \\
11 & 760 & 5.16 & 80 & 13.0105 & 3.8241 \\
12 & 827 & 5.16 & 87 & 13.0063 & 3.8221 \\
13 & 929 & 5.16 & 94 & 13.0029 & 3.8224 \\
14 & 916 & 5.16 & 101 & 13.000 & 3.8226 \\
15 & 1029 & 5.16 & 108 & 12.9975 & 3.8324 \\
16 & 1572 & 5.16 & 115 & 12.9954 & 3.8541 \\
17 & 1307 & 5.16 & 122 & 12.9936 & 3.8158 \\
\hline
\end{tabular}

Table 10 shows that the number of neurons in the hidden layer 1 varied from 3 to 17 and the sum of square error although became constant (5.16) but it was still high. This necessitated the inclusion of one more hidden layer and, therefore, one more hidden layer (hidden layer 2) was included in the network to further reduce the sum of square error. Again, the same procedure was repeated to determine the number of neurons in the hidden layer 2 . The training result for determining the number of neurons in hidden layer 2 is shown in Table 11.

Table 11. Training result for hidden layer 2 .

\begin{tabular}{cccccc}
\hline Neurons & Epochs & $\begin{array}{c}\text { Sum of } \\
\text { Square Error }\end{array}$ & $\begin{array}{c}\text { Effective } \\
\text { Parameters }\end{array}$ & $\begin{array}{c}\text { Total Number } \\
\text { of Parameter }\end{array}$ & $\begin{array}{c}\text { Sum Square } \\
\text { Parameter }\end{array}$ \\
\hline 3 & 1544 & 8.74 & 99 & 8.4655 & 3.7556 \\
4 & 1303 & 8.74 & 115 & 8.4655 & 3.7556 \\
5 & 1097 & $3.21 \times 10^{-6}$ & 131 & 60 & 39.072 \\
6 & 1205 & $4.27 \times 10^{-6}$ & 147 & 60 & 38.2852 \\
7 & 834 & $9.998 \times 10^{-8}$ & 163 & 60 & 37.0313 \\
8 & 653 & $4.70 \times 10^{-8}$ & 179 & 60 & 37.0312 \\
9 & 1528 & $5.21 \times 10^{-8}$ & 195 & 60 & 37.2152 \\
10 & 1821 & $3.11 \times 10^{-8}$ & 211 & 60 & 38.882 \\
\hline
\end{tabular}

Table 11 reveals that second layer with seven neurons reduced the sum of square error drastically from 5.16 to $9.99 \times 10^{-8}$. The architecture showing the hidden layer neurons and their possible interaction with other layer is shown in Figure 9. Thus, ANN with 3-12-7-3 architecture was trained to develop the model for predicting the output responses. A feed forward algorithm was used to train the multi-layered network. The ANN was run under certain sets of constraints, these were the stopping criterion like the number of epochs (set at 4000), the performance, i.e., error (set at $10^{-7}$ ), gradient (set at $10^{-5}$ ) etc. The program was executed and stopped at epoch 2441 as the sum of square error reached below $10^{-7}$, as shown in Figure 10. 


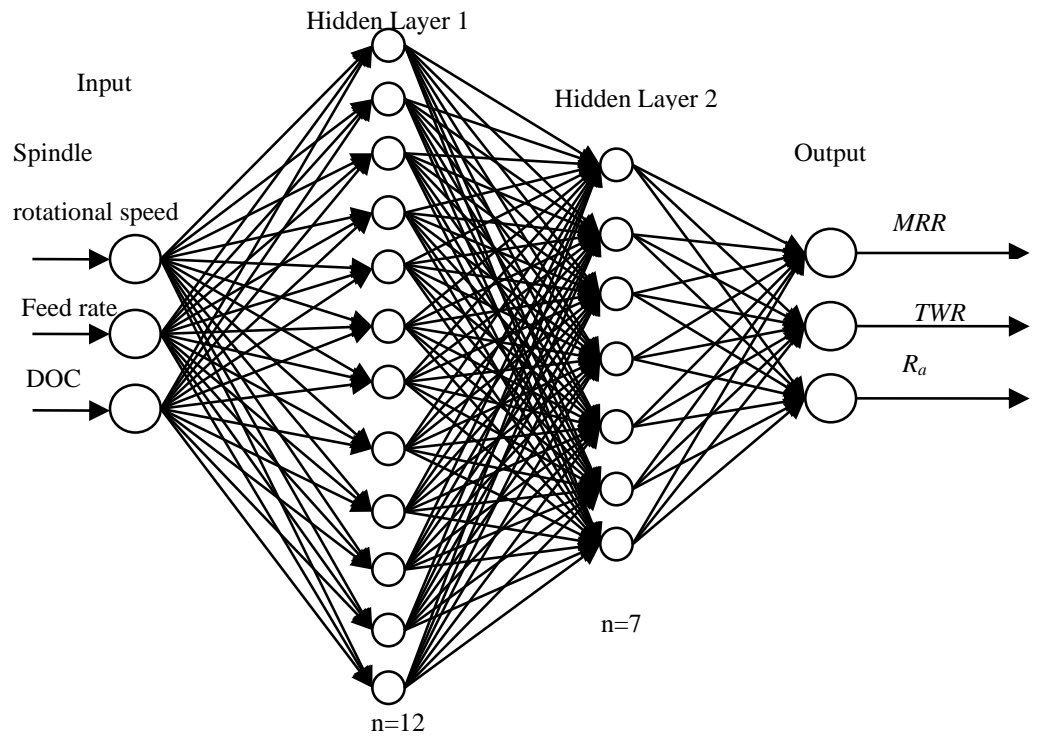

Figure 9. ANN architecture with two hidden layers.

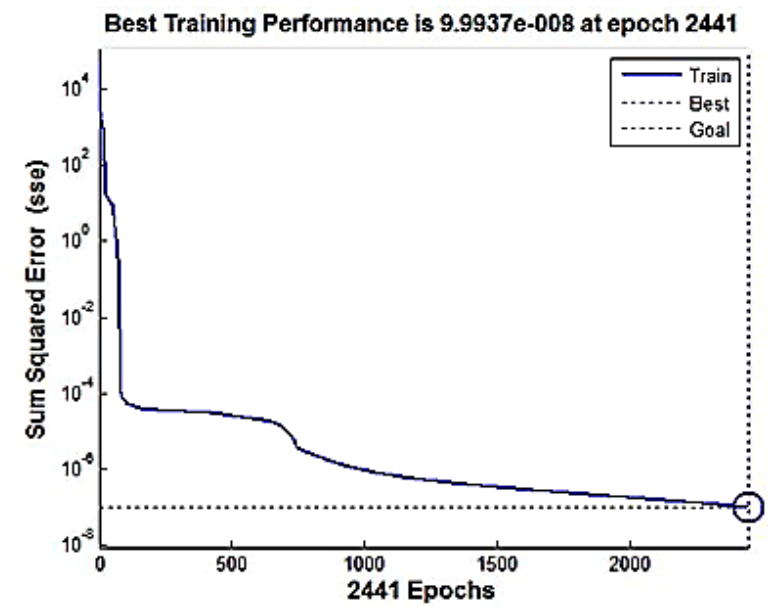

Figure 10. Training of ANN.

The regression plots were obtained for different objectives for the trained ANN which are shown in Figures 11-13.

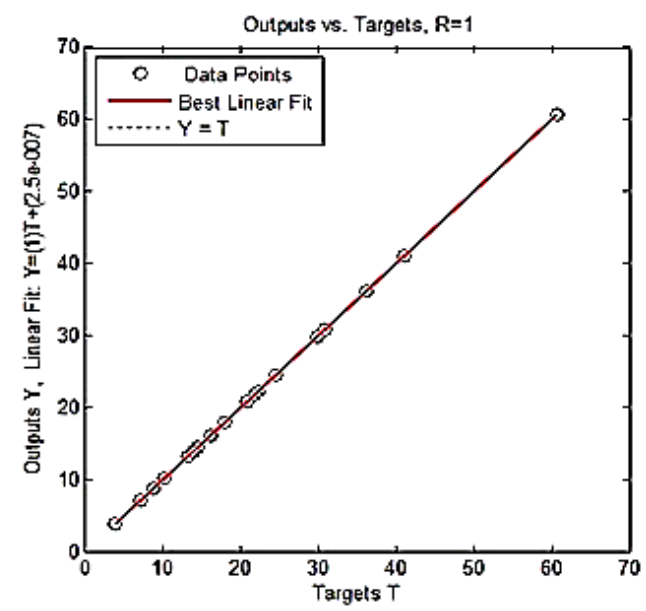

Figure 11. Regression plot of actual and network's $M R R$. 


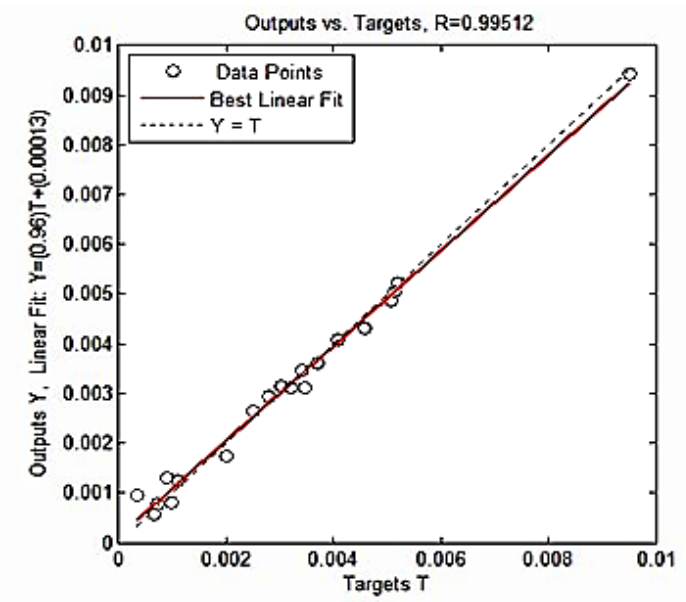

Figure 12. Regression plot of actual and network's TWR.

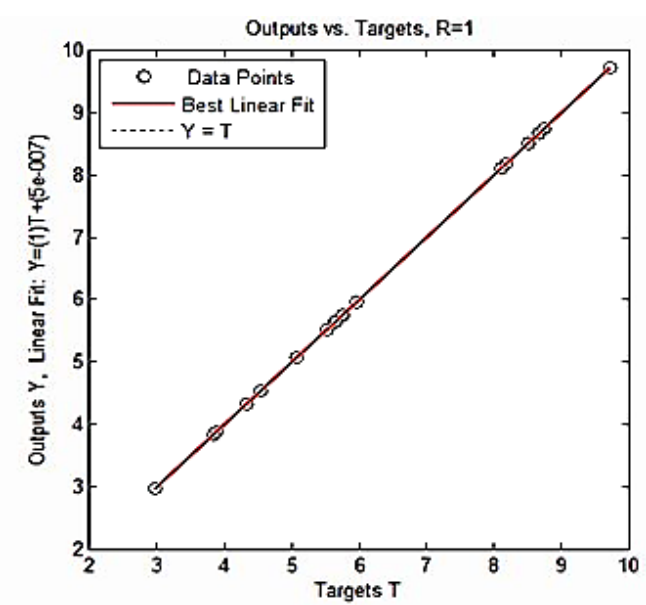

Figure 13. Regression plot of actual and network's $R_{a}$.

These plots reveal that efficiency of the trained neural network is reasonably accurate and reliable as the value of regression, i.e., $R$ is 1 .

The trained neural network was fed to the genetic algorithm as fitness function. The multi-objective GA operators considered for multi-response optimization are listed in Table 12.

Table 12. Selected GA operators.

\begin{tabular}{cc}
\hline GA Operators & Specification/Value \\
\hline Population & Bit string type \\
Population size & $15 \times$ number of variable, i.e., 45 \\
Length of chromosome & 6 \\
Initial population & generated by creation function \\
Tournament type & 4 \\
Crossover fraction & 0.8 \\
Mutation operator & Adaptive feasible \\
Number of generation & 200 \\
Function tolerance & $10^{-4}$ \\
\hline
\end{tabular}

The GA program was run in the optimized design space and the corresponding optimized output responses were recorded as shown in Table 13. 
Table 13. Optimized design space of cutting parameters and corresponding output responses.

\begin{tabular}{ccccccc}
\hline S. No. & $N$ (rpm) & $f(\mathbf{m m} / \mathbf{r e v})$ & $d(\mathbf{m m})$ & $M R R(\mathrm{~g} / \mathbf{s})$ & $T W R(\mathrm{~g} / \mathbf{s})$ & $\boldsymbol{R}_{\boldsymbol{a}}(\boldsymbol{\mu m})$ \\
\hline 1 & 346.4658 & 0.180355 & 2.211433 & 28.59589 & 0.002824 & 6.713788 \\
2 & 154.3973 & 0.100048 & 3.264468 & 7.780237 & 0.001419 & 3.782299 \\
3 & 404.0268 & 0.180004 & 3.999848 & 86.10531 & 0.007851 & 5.86492 \\
4 & 239.4459 & 0.100048 & 2.026539 & 9.082734 & $9.74 \times 10^{-4}$ & 5.008885 \\
5 & 416.5079 & 0.240917 & 3.999984 & 95.77037 & 0.009518 & 7.009632 \\
6 & 344.0623 & 0.211446 & 2.969794 & 56.68197 & 0.006029 & 9.300699 \\
7 & 344.0621 & 0.210829 & 2.969556 & 56.42865 & 0.006006 & 9.295796 \\
8 & 344.0624 & 0.181173 & 2.969974 & 44.63608 & 0.004958 & 8.796791 \\
9 & 404.0268 & 0.100048 & 3.99997 & 38.22352 & 0.00373 & 5.226101 \\
10 & 154.3973 & 0.100048 & 3.264468 & 7.780237 & 0.001419 & 3.782299 \\
11 & 239.4459 & 0.240917 & 2.026539 & 17.8303 & 0.00273 & 7.619569 \\
12 & 344.0623 & 0.211446 & 2.96955 & 56.6726 & 0.006028 & 9.300812 \\
13 & 344.0621 & 0.180004 & 2.969312 & 44.17139 & 0.004917 & 8.76704 \\
14 & 416.5073 & 0.157493 & 3.999911 & 77.02901 & 0.006955 & 5.577923 \\
15 & 404.027 & 0.153942 & 3.99997 & 73.50201 & 0.006614 & 5.503885 \\
16 & 346.4656 & 0.180397 & 2.211433 & 28.60283 & 0.002825 & 6.715555 \\
\hline
\end{tabular}

From the optimized design and objective values, various plots and curves were obtained. Figure 14 shows the optimal design variables in search space and Figure 15 exhibits the Pareto optimal solutions in three objective spaces. The Pareto solutions show a type of trade-off curve between two objectives. Consequently, after obtaining Pareto solution set one can easily carry out a trade-off study with regard to the compromise and improvement of dependent variables. For example, Figure 16 shows the trade-off between $M R R$ and TWR which reveals that TWR can be improved by compromising with $M R R$. From Figure 16 one can easily find how much $M R R$ compromise would be necessary to obtain desired amount of TWR reduction. A similar trade-off between MRR and $R_{a}$ and between TWR and $R_{a}$ are depicted in Figures 17 and 18, respectively.

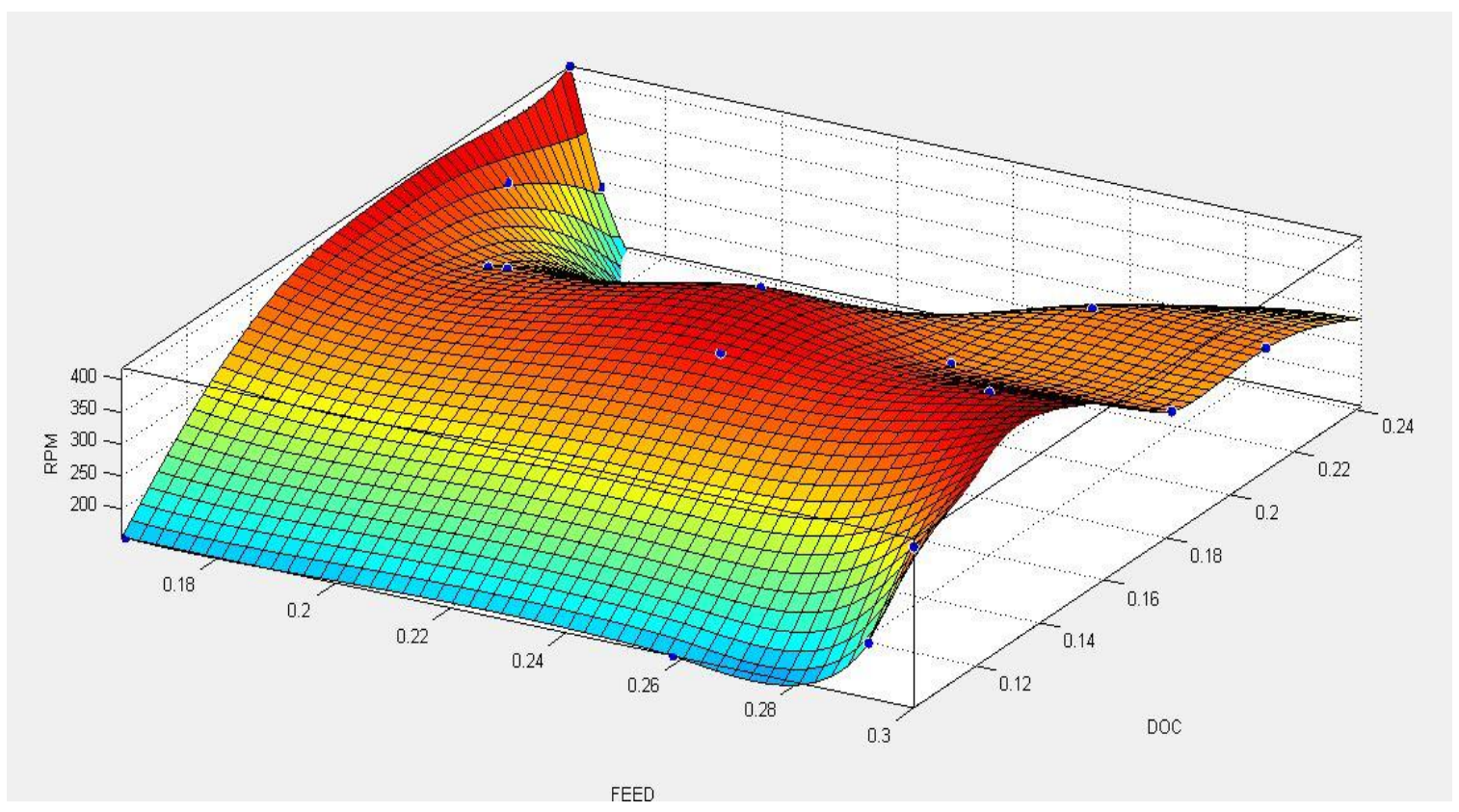

Figure 14. Optimal design variables in search space. 


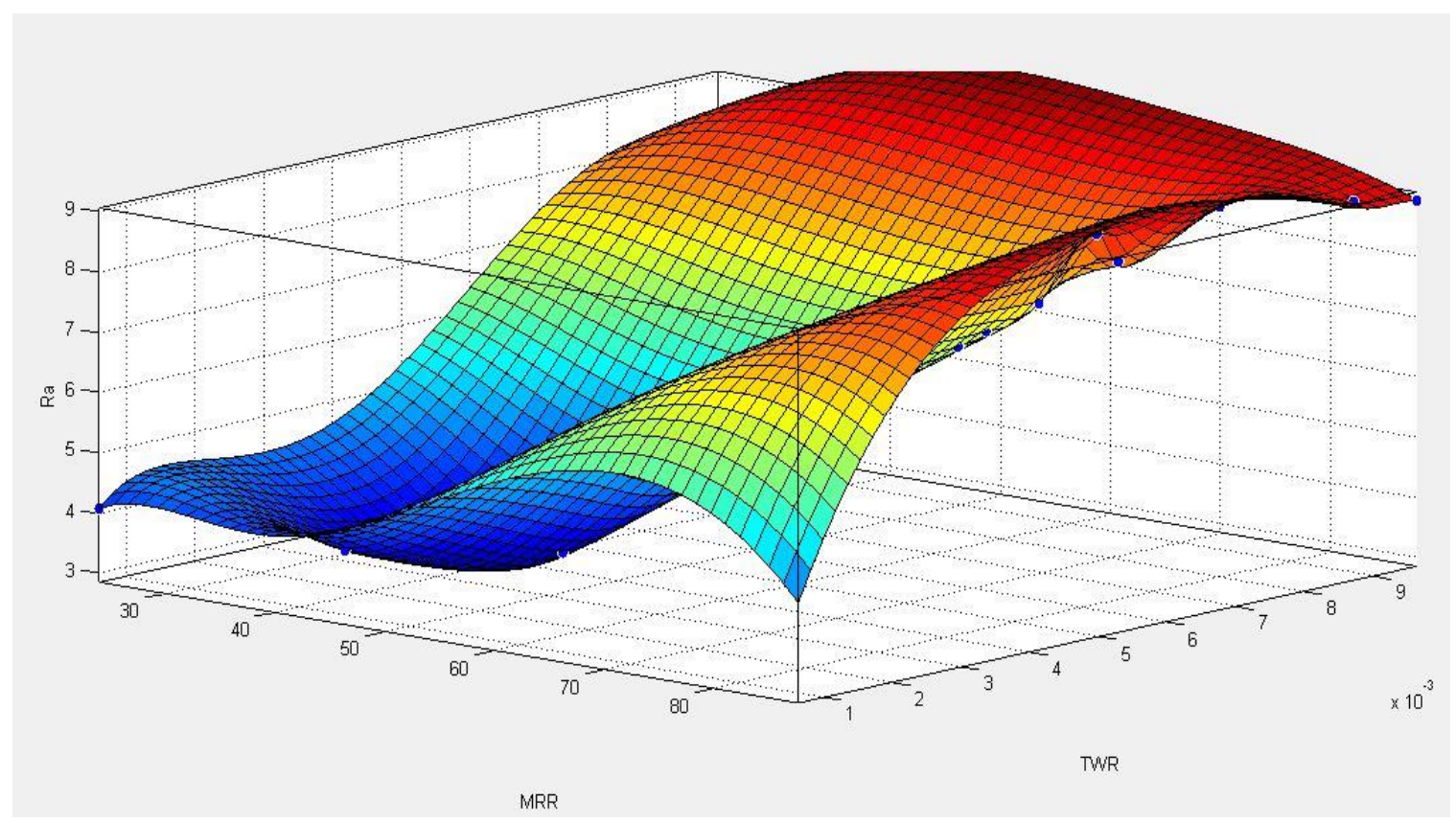

Figure 15. Pareto optimal solutions in objective space.

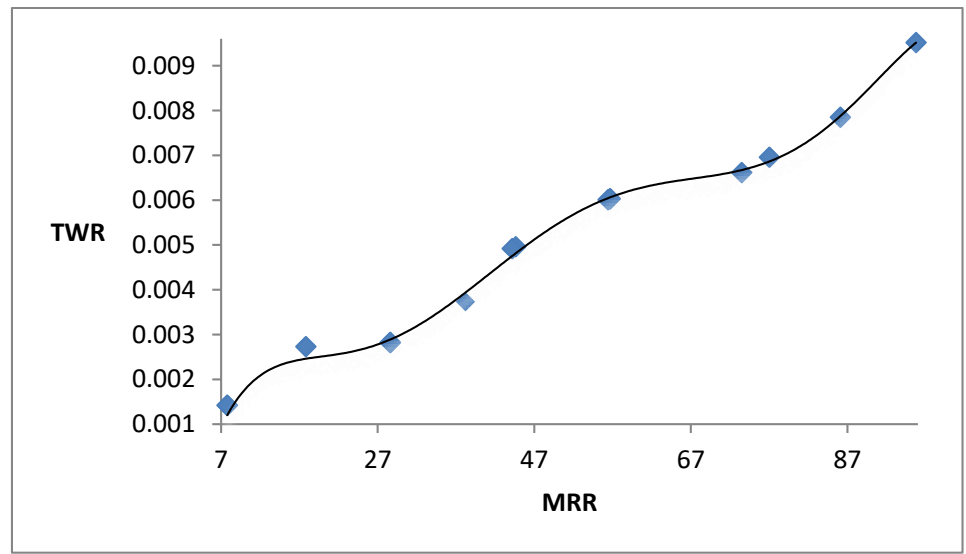

Figure 16. Pareto front between $M R R$ and TWR.

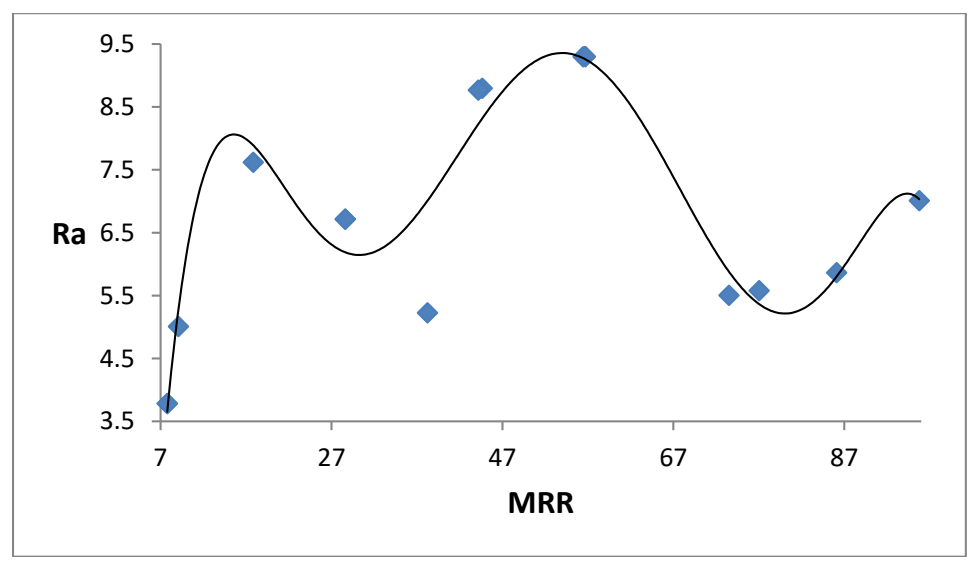

Figure 17. Pareto front between $M R R$ and $R_{a}$. 


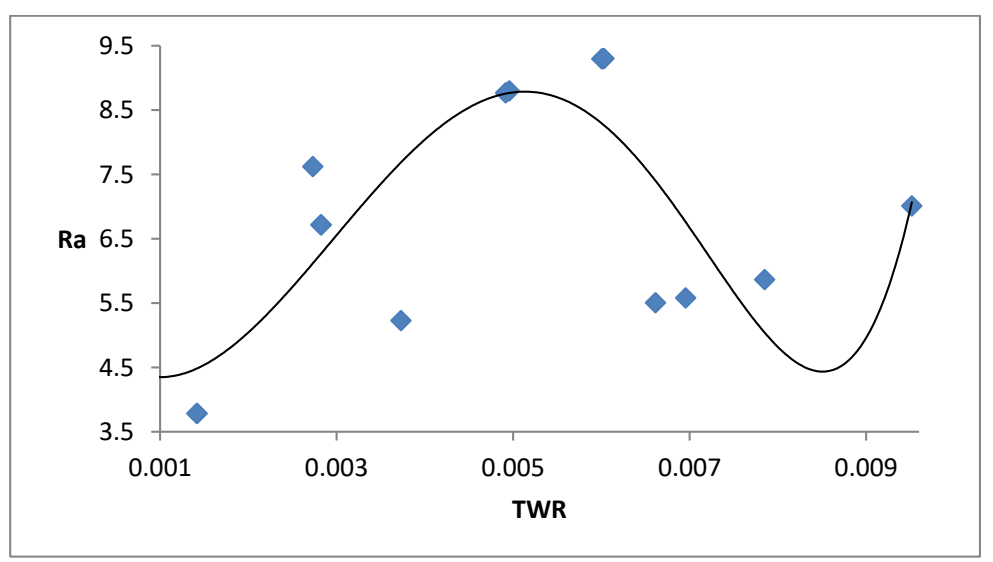

Figure 18. Pareto front between $T W R$ and $R_{a}$.

\section{Conclusions}

In the present work, turning of the GFRP composite using carbide K10 tool (Universal tool Inc., Pimpri, Maharashtra, India) was studied by varying three different cutting parameters: $N, f$ and $d$. The experiments were designed and conducted in accordance with $3^{3}$ FFDE. Output responses in terms of MRR, TWR and $R_{a}$ were measured. The ANOVA was used to study the influence of cutting parameters and their interactions on the output responses. The suitability of the model was tested using a normality test. The effect of cutting parameters and their interactions was studied and presented using surface plots. A multi-response optimization, to achieve the optimal setting of the cutting parameters, was performed using a combination of ANN and GA. ANN was used to establish the relationship between the input and output parameters and verification of the network showed that the neural network produced accurate results for obtaining objective value from any set of input parameters. The GA was used to generate the Pareto optimal solutions. The main conclusions of the present study are as under:

1. $M R R$ increases with increase in all the cutting parameters, i.e., $N, f$ and $d$. The effect of Non $M R R$ is more predominant as compared to $f$ and $d$.

2. $\quad N$ is the most influential parameter for TWR. Further, for tool wear rate the $f$ is more important than $d$. Among the three cutting parameters, the effect of $d$ is the least significant.

3. $R_{a}$ varies nonlinearly with increase in the value of $N$. It reduces with increase in $N$ up to particular value beyond which $R_{a}$ shoots up.

4. $d$ is the least significant cutting parameter for machining of GFRP composite as compared to the $N$ and $f$. However, a favorably higher value of $d$ is recommended for machining of GFRP composites.

5. The combined ANN and GA is an efficient and effective approach to solve multi-response optimization problems including the one considered in the present study as it suggests a set of alternate optimal solutions in a short period of time.

Author Contributions: Conceptualization, M.S.; Data curation, M.S. and M.I.E.; Formal analysis, M.I.E. and A.K.S.; Funding acquisition, I.A.B.; Investigation, A.E. and A.K.S.; Methodology, Z.A.K.; Resources, N.N.N.G.; Visualization, N.N.N.G.; Writing—original draft, A.E. and Z.A.K.; Writing—review \& editing, I.A.B. All authors have read and agreed to the published version of the manuscript.

Funding: This research was funded by King Khalid University, grant number R.G.P. 1/197/41.

Acknowledgments: The authors extend their appreciation to the Deanship of Scientific Research at King Khalid University, for funding this work through research groups program under grant number (R.G.P. 1/197/41).

Conflicts of Interest: The authors declare no conflict of interest. 


\section{References}

1. Ahmad, J. Introduction to polymer composites. In Machining of Polymer Composites; Springer: New York, NY, USA, 2009; pp. 1-35.

2. Ishfaq, K.; Ahmed, N. WEDM of layered composite: Analyzing material removal and cut quality issues. Mater. Manuf. Process. 2019, 34, 1073-1082. [CrossRef]

3. Pei, X.; Friedrich, K. Friction and wear of polymer composites. Ref. Modul. Mater. Sci. Mater. Eng. 2016, 1-6. [CrossRef]

4. Antil, P.; Singh, S.; Manna, A. Glass fibers/SiCp reinforced epoxy composites: Effect of environmental conditions. J. Compos. Mater. 2017, 52, 1253-1264. [CrossRef]

5. Rajak, D.K.; Pagar, D.D.; Menezes, P.L.; Linul, E. Fiber-reinforced polymer composites: Manufacturing, properties, and applications. Polymers 2019, 11, 1667. [CrossRef] [PubMed]

6. Hussain, S.A.; Pandurangadu, V.; Kumar, K.P. Optimization of surface roughness in turning of GFRP composites using genetic algorithm. Int. J. Eng. Sci. Technol. 2014, 6, 49. [CrossRef]

7. Everstine, G.; Rogers, T. A theory of machining of fiber-reinforced materials. J. Compos. Mater. 1971, 5, 94-106. [CrossRef]

8. An, S.-O.; Lee, E.-S.; Noh, S.-L. A study on the cutting characteristics of glass fiber reinforced plastics with respect to tool materials and geometries. J. Mater. Process. Technol. 1997, 68, 60-67. [CrossRef]

9. Sreenivasulu, R. Optimization of surface roughness and delamination damage of GFRP composite material in end milling using taguchi design method and artificial neural network. Procedia Eng. 2013, 64, 785-794. [CrossRef]

10. Davim, J.P.; Reis, P.; António, C. Drilling fiber reinforced plastics (FRPs) manufactured by hand lay-up: Influence of matrix (Viapal VUP 9731 and ATLAC 382-05). J. Mater. Process. Technol. 2004, 155, 1828-1833. [CrossRef]

11. Palanikumar, K.; Karunamoorthy, L.; Karthikeyan, R.; Latha, B. Optimization of machining parameters in turning GFRP composites using a carbide (K10) tool based on the taguchi method with fuzzy logics. Met. Mater. Int. 2006, 12, 483-491. [CrossRef]

12. Roy, P.K.; Basu, S.K. Evaluation of processing factors on turning of thermoplastics. Polym. Eng. Sci. 1977, 17, 751-757. [CrossRef]

13. Santhanakrishnan, G.; Malhotra, S.; Krishnamurthy, R. Machinability characteristics of fibre reinforced plastics composites. J. Mech. Work. Technol. 1988, 17, 195-204. [CrossRef]

14. Palanikumar, K. Application of Taguchi and response surface methodologies for surface roughness in machining glass fiber reinforced plastics by PCD tooling. Int. J. Adv. Manuf. Technol. 2006, 36, 19-27. [CrossRef]

15. Gupta, M. Multi-objective optimization of cutting parameters in turning using grey relational analysis. Int. J. Ind. Eng. Comput. 2013, 4, 547-558. [CrossRef]

16. Kumar, S.; Gupta, M.; Satsangi, P.; Sardana, H. Modeling and analysis for surface roughness and material removal rate in machining of UD-GFRP using PCD tool. Int. J. Eng. Sci. Technol. 2012, 3, 248-270. [CrossRef]

17. Hanafi, I.; Khamlichi, A.; Cabrera, F.M.; López, P.J.N. Prediction of surface roughness in turning of PEEK cf30 by using an artificial neural network. J. Chin. Inst. Ind. Eng. 2012, 29, 337-347. [CrossRef]

18. Eriksen, E. Influence from production parameters on the surface roughness of a machined short fibre reinforced thermoplastic. Int. J. Mach. Tools Manuf. 1999, 39, 1611-1618. [CrossRef]

19. Kini, M.V.; Chincholkar, A. Effect of machining parameters on surface roughness and material removal rate in finish turning of $\pm 30^{\circ}$ glass fibre reinforced polymer pipes. Mater. Des. 2010, 31, 3590-3598. [CrossRef]

20. Wilson, E.; Karr, C.; Messimer, S. Genetic algorithm optimization of a filament winding process modeled in WITNESS. Mater. Manuf. Process. 2003, 18, 509-521. [CrossRef]

21. Solar Chemicals and Engineers. Kolkata, West Bengal, India. Available online: https://www.tradeindia.com/ Seller-1898653-SOLAR-CHEMICALS-ENGINEERS/ (accessed on 13 August 2018).

22. Hartmetall Gesellschaft Bingmann GmbH\& Co. KG. Available online: http://www.hmtg.com/information/ grades.hartmetall (accessed on 20 August 2018).

23. Palanikumar, K.; Latha, B.; Senthilkumar, V.S.; Davim, J.P.; Kumar, K.P. Analysis on drilling of glass fiber-reinforced polymer (GFRP) composites using grey relational analysis. Mater. Manuf. Process. 2012, 27, 297-305. [CrossRef] 
24. Mudhukrishnan, M.; Hariharan, P.; Palanikumar, K.; Latha, B. Tool materials influence on surface roughness and oversize in machining glass fiber reinforced polypropylene (GFR-PP) composites. Mater. Manuf. Process. 2016, 32, 988-997. [CrossRef]

25. Patel, K.; Gohil, P.; Chaudhary, V. Investigations on drilling of hemp/glass hybrid composites. Mater. Manuf. Process. 2018, 1-12. [CrossRef]

26. Mukhopadhyay, A.; Iqbal, A. Prediction of mechanical properties of hot rolled, low-carbon steel strips using artificial neural network. Mater. Manuf. Process. 2005, 20, 793-812. [CrossRef]

27. Rajasekaran, S.; Vijaylakshmi, G.A. Introduction to artificial intelligence systems. In Neural Networks, Fuzzy Logic, and Genetic Algorithms Synthesis and Applications; PHI learning Pvt. Ltd.: New Delhi, India, 2011; pp. 1-7, ISBN 978-81-203-2186-1.

28. Harding, A.T.; Miller, I.; Freund, J.E. Probability and statistics for engineers. Math. Gaz. 1985, 69, 313. [CrossRef]

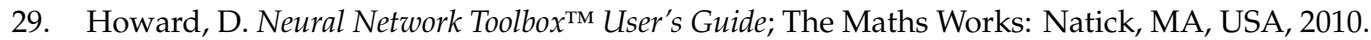

30. Equbal, A.; Equbal, M.I.; Sood, A.K. An investigation on the feasibility of fused deposition modelling process in EDM electrode manufacturing. Cirp J. Manuf. Sci. Technol. 2019, 26, 10-25. [CrossRef]

(C) 2020 by the authors. Licensee MDPI, Basel, Switzerland. This article is an open access article distributed under the terms and conditions of the Creative Commons Attribution (CC BY) license (http://creativecommons.org/licenses/by/4.0/). 